\title{
Crystalline and electronic structure of $\mathrm{Pu}-\mathrm{Ce}$ and $\mathrm{Pu}-\mathrm{Ce}-\mathrm{Ga}$ alloys stabilized in the $\delta$ phase
}

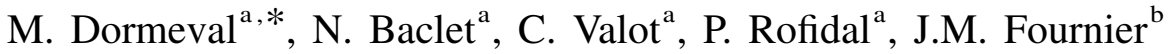 \\ ${ }^{a} C E A$-Centre de Valduc, 21120 Is sur Tille, France \\ ${ }^{\mathrm{b}}$ Université Joseph Fourier LEG-INPG, BP 46, 38402 Saint Martin d'Hères Cedex, France
}

\begin{abstract}
In the actinides series (which corresponds to the progressive filling of the $5 \mathrm{f}$ sub-shell), plutonium lies at the changeover for the behavior of the $5 \mathrm{f}$ electrons between the light actinides (up to $\mathrm{Np}$ ) with delocalized $5 \mathrm{f}$ states, and the heavy actinides (from Am on) with localized $5 \mathrm{f}$ states. At this boundary, the expanded $\delta$-phase exhibits an intermediate and thus controversial behavior of its $5 \mathrm{f}$ electrons. This high temperature $\delta$-phase can be stabilized at and below room temperature by alloying with so-called deltagen solutes $\mathrm{Ga}, \mathrm{Al}, \mathrm{Ce}$ and $\mathrm{Am}$. In this work, some $\mathrm{Pu}-\mathrm{Ce}$ and $\mathrm{Pu}-\mathrm{Ce}-\mathrm{Ga}$ alloys were studied using several techniques (dilatometry, X-ray diffraction (XRD), extended X-ray absorption fine structure spectroscopy (EXAFS), electrical resistivity and magnetic susceptibility). It is found that the mechanism of $\delta$-Pu stabilization is far from straightforward as both $\mathrm{Pu} 5 \mathrm{f}$ and $\mathrm{Ce} 4 \mathrm{f}$ electronic states are involved, inducing complex crystalline organization while no clear localization of the $5 \mathrm{f}$ states can be deduced from experimental results. Ternary Pu-Ce-Ga alloys show cooperative deltagen effects of $\mathrm{Ce}$ and $\mathrm{Ga}$.
\end{abstract}

Keywords: Actinide alloys; EXAFS; X-ray diffraction; Magnetic measurements

\section{Introduction}

In the actinides series, corresponding to the progressive filling of the $5 \mathrm{f}$ sub-shell, plutonium $(\mathrm{Pu})$ lies at the crossover between two sub-families, the light and the heavy actinides: the light actinides (from protactinium $(\mathrm{Pa})$ to neptunium $(\mathrm{Np}))$ in which the $5 \mathrm{f}$ electrons are bonding and exhibit a band character similar to that of d electrons in transition metals, and the heavy actinides (from americium (Am) to lawrencium (Lw)) with localized, nonbonding, $5 \mathrm{f}$ electrons comparable to the $4 \mathrm{f}$ electrons in the lanthanide series. Moreover, this transition from delocalization to localization of the $5 \mathrm{f}$ electrons in the actinides takes place within the plutonium phase diagram, following its numerous allotropic changes $\left(\alpha, \beta, \gamma, \delta, \delta^{\prime}, \varepsilon\right)$ and the associated volume changes, focusing on the $\alpha-\delta$ transition.

At room temperature, plutonium is monoclinic $(\alpha-\mathrm{Pu})$ and most people now agree that the $5 \mathrm{f}$ electron states, although correlated, are itinerant in this phase. Between 592 and $730 \mathrm{~K}$, plutonium is face-centered-cubic (f.c.c.

*Corresponding author.

E-mail address: marion.dormeval@cea.fr (M. Dormeval).
$\delta-\mathrm{Pu})$ and various experimental and theoretical approaches $[1,2]$, corroborate the straightforward volume information: $\delta-\mathrm{Pu}$ is intermediate between $\alpha-\mathrm{Pu}$ and $\mathrm{Am}$ and so is the behavior of its $5 \mathrm{f}$ electrons. While theoretical studies can be performed without any problem on pure $\delta$-Pu even at $T=0$, experimentally, it is necessary to chemically stabilize this high temperature phase at and below room temperature by alloying in order to investigate this allotrope using usual techniques. In doing so, the true structure of pure $\delta$ - $\mathrm{Pu}$ is perturbed and one is then obliged to study the behavior of the alloys as a function of composition in order to obtain the behavior of pure $\delta$-Pu by extrapolation. On the other hand, these studies in themselves may help to better understand the stabilization mechanisms and thus the electronic structure of pure $\delta$-Pu.

Only four such deltagen elements exist leading to substitutional solid solutions of $\delta$-stabilized $\mathrm{Pu}$ alloys at and below room temperature: gallium $(\mathrm{Ga})$, aluminum $(\mathrm{Al})$, cerium $(\mathrm{Ce})$ and americium $(\mathrm{Am})$. The case of scandium $(\mathrm{Sc})$ is more controversial since for both Ellinger et al. [3] and Kutaitsev et al. [4] the phase diagram at room temperature remains uncertain.

While $\mathrm{Ga}$ and $\mathrm{Al}$ atoms are smaller than $\delta-\mathrm{Pu}, \mathrm{Ce}$ and 
Am are larger so that a priori the size of dopant does not seem to be the primary control parameter. $\mathrm{Ga}$ and $\mathrm{Al}$ atoms $\left(r_{\mathrm{Ga}}=1.41 \AA^{1}, r_{\mathrm{Al}}=1.43 \AA\right)$ are respectively 14 and $13 \%$ smaller than $\delta$-Pu atoms $\left(r_{\delta-\mathrm{Pu}}=1.64 \AA\right)$. They stabilize the $\delta$-phase for $\mathrm{Ga}$ and $\mathrm{Al}$ contents ranging from 0.8 to 10 at.\% and 2.5 to 10 at.\%, respectively. X-ray diffraction (XRD) studies performed on different $\mathrm{Pu}-\mathrm{Ga}$ [8] and $\mathrm{Pu}-\mathrm{Al}$ [9] alloys show not only a decrease in the lattice parameter but even a negative deviation from Vegard's law with increasing $\mathrm{Ga}$ and $\mathrm{Al}$ contents. Extended X-ray absorption fine structure spectroscopy (EXAFS) investigations of $\mathrm{Pu}-\mathrm{Ga}$ alloys $[10,11]$, have shown $\mathrm{Ga}$ to be substitutional with an almost $4 \%$ shrinkage of the nearest plutonium atoms towards the $\mathrm{Ga}$ atoms. According to the authors, this contraction suggests hybridization between Ga $4 p$ electronic states and plutonium $5 f$ electronic states which explains the decrease in the $\delta$-Pu radius resulting in the observed negative deviation from Vegard's law.

This approach is corroborated by theoretical calculations [12], unpublished calculations by Eriksson and Boring, cited by Cox et al. [11]. Thus one could surprisingly conclude that $\mathrm{Ga}(\mathrm{Al})$ atoms stabilize the $\delta$ phase through $4 p(3 p)-5 f$ hybridization, i.e. $5 f$ electron states delocalization, more precisely by replacing $6 \mathrm{~d}-5 \mathrm{f}$ hybridization by $4 p(3 p)-5 f$ hybridization when substituting Pu by $\mathrm{Ga}(\mathrm{Al})$. This mechanism for $\delta$-phase stabilization is in agreement with more recent theories [13] in which the broadening of the $5 \mathrm{f}$ bands favors higher symmetry crystal structures.

Another possibility could be hybridization between the ligand $4 p(3 p)$ electron states and $\mathrm{Pu} 6 \mathrm{~d}$ electron states, which would then reduce the $5 \mathrm{f}-6 \mathrm{~d}$ hybridization and then leave the $5 f$ states more localized [14]. However, no such localization is experimentally observed by, e.g. magnetic susceptibility measurements.

Ce and Am atoms $\left(r_{\alpha-\mathrm{Ce}}=1.71 \AA, r_{\gamma-\mathrm{Ce}}=1.82 \AA, r_{\beta-\mathrm{Am}}=\right.$ $1.73 \AA$ ) are respectively 4,11 and $5.5 \%$ larger than $\delta-\mathrm{Pu}$ atoms. Am stabilizes $\delta$-Pu for contents ranging from 5 to 76 at. $\%$. Ce stabilizes $\delta$-Pu for contents ranging from 4.5 to 17 at.\%. Between 17 at.\% and 75 at.\% Ce, the solid solution can be quenched at room temperature and is again stable between 75 and 100 at.\% of Ce [15].

Both $\mathrm{Pu}-\mathrm{Ce}$ and $\mathrm{Pu}-\mathrm{Am}$ alloys have been much less studied than $\mathrm{Pu}-\mathrm{Al}$ or $\mathrm{Pu}-\mathrm{Ga}$ alloys. Handling of $\mathrm{Pu}-\mathrm{Am}$ alloys presents obvious difficulties due to the high radioactivity of Am. Results on $\mathrm{Pu}-\mathrm{Am}$ will be presented in forthcoming papers but preliminary XPS measurements [16] showed effectively a localization of the $5 \mathrm{f}$ electron states for americium contents higher than 25 at.\%.

This work describes the behavior of $\mathrm{Ce}$ regarding the stability of $\delta$-Pu as studied both from a crystalline structure point of view (thermal expansion, XRD, EXAFS) and an electronic structure point of view (electrical resistivity, magnetic susceptibility).

\footnotetext{
${ }^{1}$ Radii are calculated using a coordination number of twelve for gallium [5], aluminum [5], americium [6], and cerium [7].
}

The $\mathrm{Pu}-\mathrm{Ce}$ alloys are all the more interesting because $\mathrm{Ce}$ and $\mathrm{Pu}$ exhibit very related electronic properties linked to the anomalous character of the $\mathrm{f}$ states: both $4 \mathrm{f}$ states in $\mathrm{Ce}$ and $5 \mathrm{f}$ states in $\mathrm{Pu}$ are at the threshold of localization. Thus, in $\delta$-Pu-Ce alloys, Ce can be in the $\gamma$-Ce form or in the $\alpha$-Ce form depending on the composition. Moreover, since two different mechanisms ( $\mathrm{f}-\mathrm{p}$ hybridization and $\mathrm{f}$ localization) both lead to the stabilization of the $\delta-\mathrm{Pu}$ phase, ternary $\mathrm{Pu}-\mathrm{Ce}-\mathrm{Ga}$ alloys were also studied in order to determine if $\mathrm{Ga}$ and $\mathrm{Ce}$ had an antagonist or a cooperative effect when both present. Experimental details are described in Section 2. Results are given in Section 3 and discussed from crystalline and electronic structures's points of views in Section 4 before concluding.

\section{Experimental details}

\subsection{Samples}

Four binary $\mathrm{Pu}-\mathrm{Ce}$ alloys and two ternary $\mathrm{Pu}-\mathrm{Ce}-\mathrm{Ga}$ alloys were synthesized. Alloys were made from solid or powdery Ce (99.9 wt.\%), and solid Ga (99.99 wt.\%) and $\mathrm{Pu}$ pieces. Weightings of $\mathrm{Pu}(500 \mathrm{~g}$ ), Ce (from 3 to $33 \mathrm{~g}$ ) and, for the ternary alloys, $\mathrm{Ga}(1.3 \mathrm{~g})$, were placed in tantalum crucibles and induction melted at $1373 \mathrm{~K}$ for $2 \mathrm{~h}$. The mixtures were then casted into graphite moulds at 773 $\mathrm{K}$ and cooled down to room temperature. After the machining of the ingots into samples of required geometry, a heat treatment at $733 \mathrm{~K}$ for $200 \mathrm{~h}$ under high vacuum was performed to homogenize the solute concentrations. Chemical analyses are displayed in Table 1. Results are given in atomic percent, as in all the following.

\subsection{Experimental set-up}

The thermal expansion experiments were performed in a glove box, using a horizontal dilatometer (Adamel, Di22) under $\mathrm{Ar}$ atmosphere. The other experiments were performed in devices that were not in glove boxes.

XRD experiments were made in a classical $\theta-2 \theta$ diffractometer (Siemens, D500) with copper radiation, secondary graphite monochromator, scintillation detector. The lattice parameter was measured with an accuracy of $\pm 5 \cdot 10^{-4} \AA$.

Table 1

Chemical analyses performed on $\mathrm{Pu}-\mathrm{Ce}$ and $\mathrm{Pu}-\mathrm{Ga}-\mathrm{Ce}$ alloys. Impurity contents were lower than 30 wt. ppm for $\mathrm{Ni}, \mathrm{Fe}$, and $\mathrm{Cr}$

\begin{tabular}{lll}
\hline $\begin{array}{l}\text { Ce at.\% } \\
( \pm 0.3)\end{array}$ & $\begin{array}{l}\text { Ga at.\% } \\
( \pm 0.1)\end{array}$ \\
\hline 3.5 & - & Under Ce stability limit \\
4.6 & - & Ce stability limit \\
6.1 & - & \\
8.1 & - & Ga stability limit \\
4.0 & 0.9 & \\
3.7 & 1.9 & \\
\hline
\end{tabular}


EXAFS experiments were performed at LURE (beam DCI D44, Orsay, France) in a liquid nitrogen cryostat. Spectra were recorded in the transmission mode at the $\mathrm{Pu}$ $\mathrm{L}_{\mathrm{III}}$-edge $(18053 \mathrm{eV})$, and in the fluorescence mode (with a 7-elements detector) at the $\mathrm{Ce}_{\mathrm{III}}$-edge $(5727 \mathrm{eV})$ and $\mathrm{Ga}$ K-edge $(10367 \mathrm{eV})$. The interatomic distances are obtained with an accuracy of $\pm 0.01 \AA$. For both XRD and EXAFS measurements, the samples were confined in a plastic film allowing a good transparency to X-rays, and were placed in a sample holder.

The magnetic susceptibility device was studied by means of a Faraday balance equipped with a helium cryostat. Experiments were performed from room temperature down to $4 \mathrm{~K}$ (cooling rate of $1 \mathrm{~K} / \mathrm{min}$ ) at 0.8 and 1.4 Tesla. Samples were first sealed in a quartz tube (under $\mathrm{He}$ atmosphere), then placed in gold cylinders (to reduce the magnetic response from the sample holder), and finally enclosed in aluminum containers (under $\mathrm{He}$ atmosphere). The total susceptibility of the sample holder did not exceed $2.10^{-7} \mathrm{emu}$, and the susceptibility corrected from the sample holder contribution was given with an accuracy of $\pm 8.10^{-6} \mathrm{emu} / \mathrm{mole}$.

For electrical resistivity measurements, a $500 \mu \mathrm{m}$ thick sample (surface $2 \times 5 \mathrm{~mm}^{2}$ ) was electropolished and confined in a copper sample holder (under $\mathrm{He}$ atmosphere). Inside, the sample was maintained by four leads pressed on the sample; these ensured current flow and voltage pickup. Experiments were performed from room temperature down to $4 \mathrm{~K}$ with a helium cryostat $(1 \mathrm{~K} / \mathrm{min})$. The resistance was measured with an accuracy of $\pm 4 \mu \Omega$. The 4-points method unfortunately leads to a high incertitude in the determination of the resistivity $\rho$ from the measured resistance $R$, mainly because of the small size of the sample, the size of the contacts, and the thin section approximation $^{2}$. Thus, the normalized $\rho / \rho_{295 K}$ values were considered for quantitative comparison between different alloys.

\section{Results}

\subsection{Thermal expansion}

Thermal expansion of the four binary and two ternary alloys has been measured between 300 and $775 \mathrm{~K}$. While the coefficient of thermal expansion $\alpha$ is always positive just above room temperature, it becomes negative at high temperature for low solute content, as for pure $\delta-\mathrm{Pu}(\delta-\mathrm{Pu}$

\footnotetext{
${ }^{2}$ Relation between the resistance and the resistivity in the thin section approximation:

$R=\rho \times \frac{1}{2 e \pi} \ln \frac{\left(S_{1}+S\right)\left(S_{2}+S\right)}{S_{1} S_{2}}$

where $R$ is the resistance, $\rho$ the resistivity, $e$ the sample thickness and $S_{1}, S_{2}, S$ the distances between the leads [17].
}

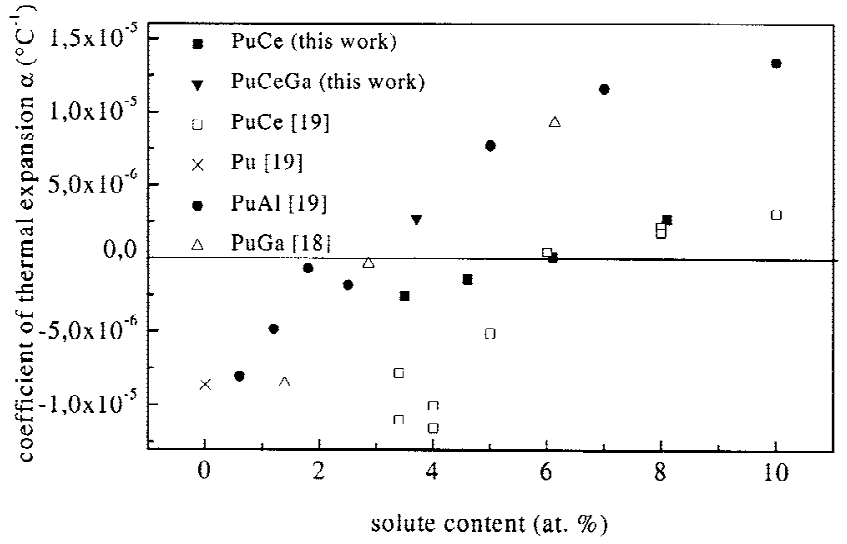

Fig. 1. Coefficient of thermal expansion $\alpha$ (taken between 592 and 730 $\mathrm{K})$ vs. deltagen content for binary $\mathrm{Pu}-\mathrm{Ce}$ ([19], this work), Pu-Ga [18] and $\mathrm{Pu}-\mathrm{Al}[19]$ alloys, and ternary $\mathrm{Pu}-\mathrm{Ce} 3.7 \%-\mathrm{Ga} 1.9 \%$ alloy (this work), for which $\alpha$ is plotted vs. the sum of $\mathrm{Ga}$ and $\mathrm{Ce}$ contents.

being stable between 592 and $730 \mathrm{~K}$ ). Fig. 1 displays the change in $\alpha$ with Ce content, together with previous results on $\mathrm{Pu}-\mathrm{Ga}$ and $\mathrm{Pu}-\mathrm{Al}$ alloys and pure $\delta$-Pu metal in the temperature range where pure $\delta$-Pu is stable and $\alpha$ essentially independent of temperature. Also shown is the $\alpha$ coefficient of the ternary PuCe3.7\%Ga1.9\% alloy. Pu$\mathrm{Ga}$ and $\mathrm{Pu}-\mathrm{Al}$ alloys follow the same trend whereas the change in $\alpha$ vs. solute content is different for $\mathrm{Pu}-\mathrm{Ce}$ alloys. Results for low Ce contents show a strong dispersion that could be attributed to non monophased samples $(\alpha+\delta$ mixture) since the Ce content is close to the stability limit of the $\delta$-phase.

\section{2. $X R D$ and $E X A F S$}

The PuCe $3.5 \%$ alloy with a Ce concentration below the reported stability limit has been found polyphased, containing some $\gamma$-phase. All the other alloys including $\mathrm{PuCe} 4.6 \%$ at the stability limit and $\mathrm{PuCe} 3.7 \% \mathrm{Ga} 1.9 \%$ where $\mathrm{Ce}$ content is below the stability limit are single phased. This last result already shows that stabilization effects by $\mathrm{Ce}$ and $\mathrm{Ga}$ are cooperative.

All XRD spectra exhibit similar narrow lines except for the richest in $\mathrm{Ce}, \mathrm{PuCe} 8.1 \%$ for which a broadening is clearly observable (Fig. 2).

The mean interatomic distance of the binary alloys increases gradually with the Ce content, as expected, but a discrepancy from Ellinger's results [20] is systematic. This cannot be explained by diffractometer calibration (carefully checked) nor chemical analysis errors as our measured concentrations give very good agreement with existing data for other physical properties. These results together with ternary XRD data and EXAFS data are reported in Fig. 3. EXAFS spectra obtained at the $\mathrm{L}_{\mathrm{III}}$-edge of $\mathrm{Ce}$ are of poor quality (low energy of the $\mathrm{L}_{\mathrm{III}}$-edge, influence of the $\mathrm{Pu} \mathrm{M}$-edges ... ); in that case, information was limited 


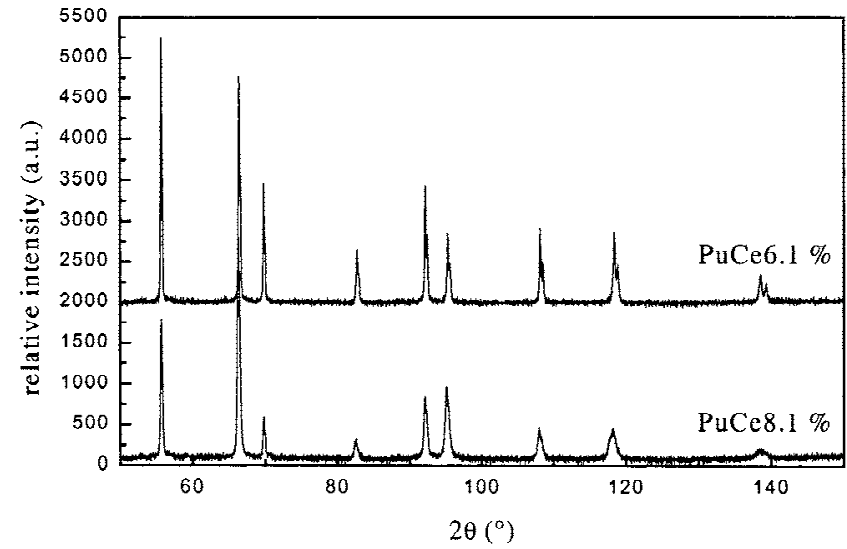

Fig. 2. XRD diagrams of the $\mathrm{Pu}-\mathrm{Ce} 8.1 \%$ and $\mathrm{Pu}-\mathrm{Ce} 6.1 \%$, showing wider peaks for the PuCe8.1\%.

to the first coordination shell and only two alloys were analyzed satisfactorily.

Surprisingly, $\mathrm{Pu}-\mathrm{Pu}$ distances obtained by EXAFS are both smaller than those deduced from XRD and essentially constant at a $3.27 \AA$ value, in agreement with recent results obtained by Villela et al. [21] on PuCe10\%. This behavior is not observed in $\mathrm{Pu}-\mathrm{Ga}$ alloys [10] and no explanation for this surprising result is found yet.

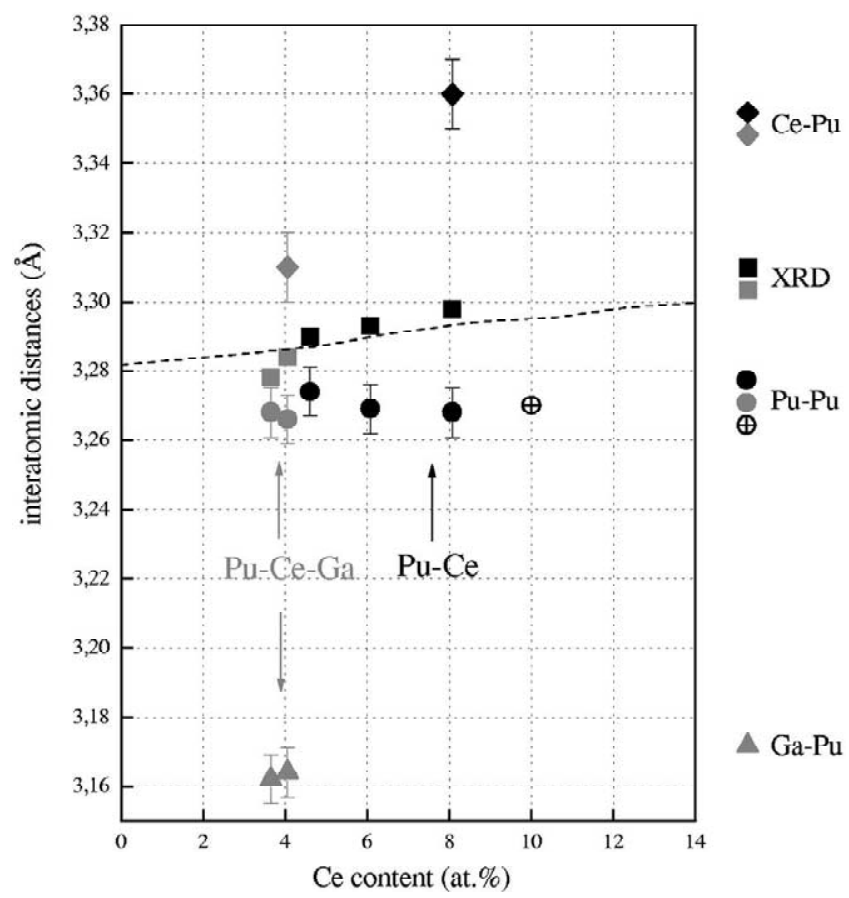

Fig. 3. Change in the first atomic distance around $\mathrm{Pu}, \mathrm{Ce}$ and $\mathrm{Ga}$ atoms, measured by EXAFS. Black plots correspond to the $\mathrm{Pu}-\mathrm{Ce}$ binary alloys and the gray plots correspond to the ternary $\mathrm{Pu}-\mathrm{Ce}-\mathrm{Ga}$ alloys. Empty circle enclosing a cross is extracted from Ref. [21] and the dashed line has been deduced from XRD measurements by Ref. [20].

\subsection{Electrical resistivity}

Electrical resistivity measurements on the six alloys together with literature data on $\mathrm{Pu}-\mathrm{Ga}$ alloys are reported in Fig. 4 in which the martensitic transformation in $\mathrm{PuCe} 4.6 \%$ is clearly visible. As it has been pointed out in Section 2, while our miniature four points apparatus allows to measure the resistance of small samples with arbitrary shape, it has the severe drawback to lead to a high uncertainty in the determination of the absolute resistivity. This prevents to compare the resistivity of different alloys as well as to compare our measurements with literature data.

Assuming that Matthiessen rule is followed, it is usual to write the electrical resistivity $\rho$ as the sum of three contributions

$\rho=\rho_{0}+\rho_{\mathrm{ph}}+\rho_{\mathrm{mag}}$,

where $\rho_{0}$ is the residual resistivity due to impurities and defects, $\rho_{\mathrm{ph}}$ is the lattice resistivity due to scattering by phonons and $\rho_{\text {mag }}$ is the magnetic resisitivity due to spin scattering. Apart from defects annealing, $\rho_{0}$ is constant, while $\rho_{\mathrm{ph}}$ is essentially linear above $20 \mathrm{~K}\left(\theta_{\mathrm{D}} / 10\right.$, where $\theta_{\mathrm{D}}$ is the Debye temperature). $\delta$-Pu having the f.c.c. structure of thorium (Th), it is usual to assume similar contributions for $\rho_{0}$ and $\rho_{\mathrm{ph}}$ between $\delta$-Pu, its alloys and Th [23]. Thus these terms represent no more than $10 \%$ of the total resistivity at room temperature and only $4 \%$ at $100 \mathrm{~K}$ : the magnetic contribution due to the $5 \mathrm{f}$ electrons represents most of the total resistivity. The abundant literature data on $\delta$-Pu alloys show that $\rho(T)$ values converge quite well towards a common room temperature value following a large plateau above $150 \mathrm{~K}$. This is in apparent contradiction with the Matthiessen rule except if the $\rho_{0}$ value is negligible compared to the $\left(\rho_{\mathrm{ph}}+\rho_{\mathrm{mag}}\right)$ value. From the above consideration about thorium, this seems to be the case for $\delta$-Pu alloys. This allows to use normalized values $\rho(T) / \rho(295 \mathrm{~K})$ for quantitative comparison between different alloys and also with literature data. As an example, Fig. 5 shows an excellent agreement between our results and Elliott's ones [17], while absolute values are very different.

Using this method it is also possible to extrapolate the normalized resistivity to $0 \mathrm{~K}$ and Fig. 6 shows $\rho(0 \mathrm{~K}) /$ $\rho(295 \mathrm{~K})$ vs. solute content for $\mathrm{Pu}-\mathrm{Ce}, \mathrm{Pu}-\mathrm{Ga}$ and $\mathrm{Pu}-\mathrm{Al}$ systems. The similar behavior for $\mathrm{Pu}-\mathrm{Ga}$ and $\mathrm{Pu}-\mathrm{Al}$ systems is consistent with the strong similarities between these two solutes as deltagen elements. The differences between $\mathrm{Pu}-\mathrm{Ce}$ and $\mathrm{Pu}-\mathrm{Ga}$ alloys suggests different electronic modification due to alloying. For the ternary alloys, both looking at them as adding $\mathrm{Ce}$ to $\mathrm{Ga}$ or $\mathrm{Ga}$ to Ce lead systematically to an increase in $\rho(0 \mathrm{~K}) / \rho(295 \mathrm{~K})$.

For all the considered systems $(\mathrm{Pu}-\mathrm{Ga}, \mathrm{Pu}-\mathrm{Al}, \mathrm{Pu}-\mathrm{Ce})$ the normalized resistivity vs. solute content has been extrapolated to pure $\delta$ - $\mathrm{Pu}(0 \%$ solute content) at different temperatures. It is quite remarkable that these extrapolations lead to values that are independent of the nature of 


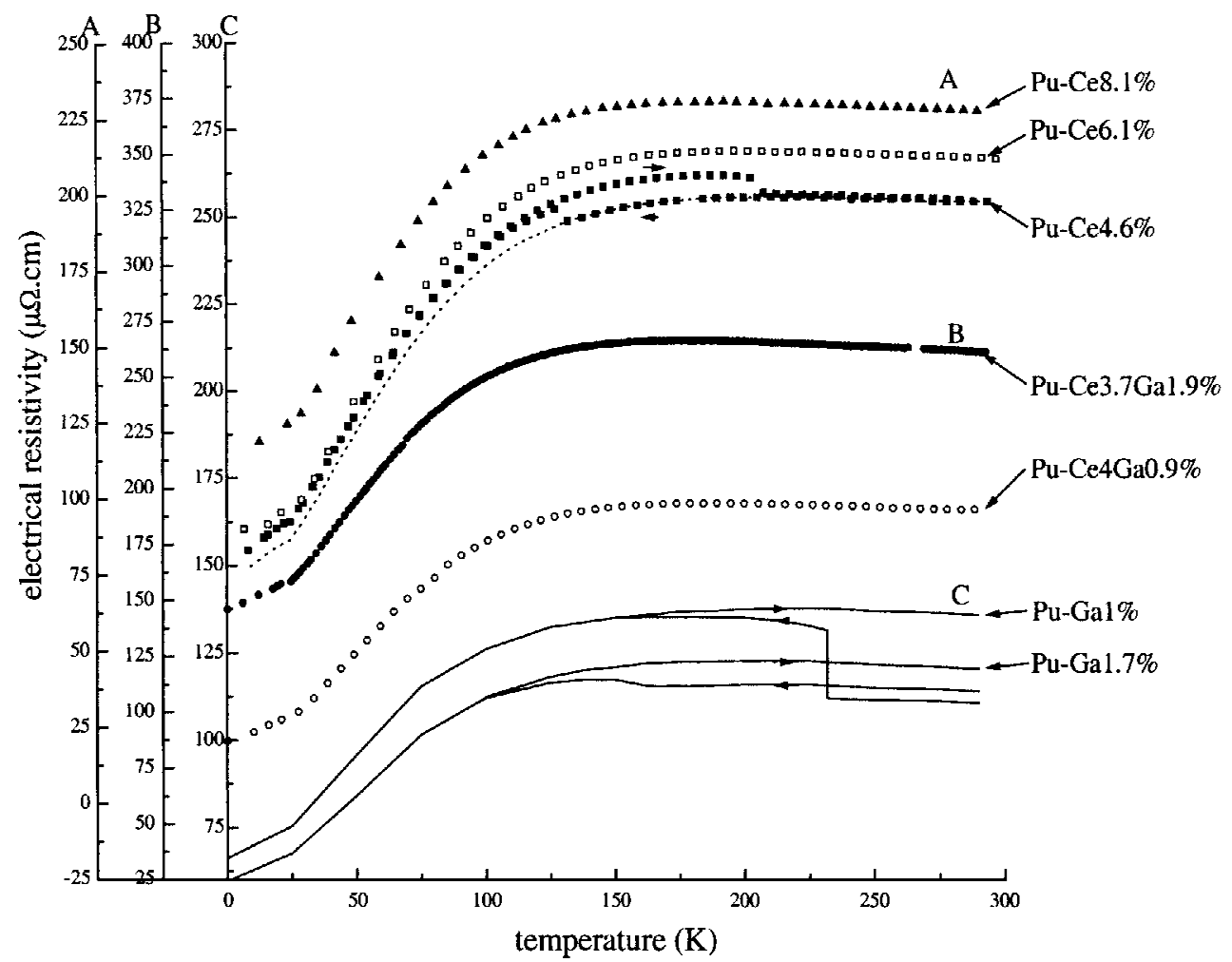

Fig. 4. Electrical resistivity change versus temperature, for binary Pu-Ce (this work) and Pu-Ga [22] alloys, and ternary Pu-Ce-Ga alloys (this work). A loss of electrical contact appeared at $50 \mathrm{~K}$ (decreasing temperature) for the $\mathrm{Pu}-\mathrm{Ce} 3.6 \%$ alloy; this was not restored during the temperature increase.

the solute within the accuracy of our measurements. It is then possible to represent the variation $\rho(T)$ of an hypothetical pure $\delta$-Pu below the stability limit of this phase $(592 \mathrm{~K})$. Values are available only for temperature lower than $295 \mathrm{~K}$ since measurements have been performed between 295 and $4 \mathrm{~K}$. This is displayed in Fig. 7 in which this curve seems to link up very well with the experimental one at the temperature of phase stability limit.

\subsection{Magnetic susceptibility}

True susceptibility values were obtained from the linear part of the magnetization $\mathrm{M}(\mathrm{H})$ after saturation of magnetic impurities. For all binary and ternary alloys, the susceptibility is essentially constant within the experimental accuracy which is about $1.5 \%$. These results are reported in Fig. 8 together with previous results published on PuCe6\%. No attempt to Curie-Weiss fit is possible on these flat $\chi(T)$ curves.

Thus, neither a temperature dependence nor a solute concentration dependence can be observed. This behavior is similar to that of $\mathrm{Pu}-\mathrm{Ga}$ and $\mathrm{Pu}-\mathrm{Al}$ alloys and no evidence of localization through Curie-Weiss behavior is obtained.

A much higher and temperature dependent susceptibility was obtained in Ref. [25] on Pu-Ce 6\% alloys. However, it was noted that the alloy was not single phased. Our measurements show that this behavior must not be attributed to $\delta$-PuCe6\%.

The martensitic transformation observed in $\mathrm{PuCe} 4.6 \%$ by electrical resistivity measurements is not detectable by magnetic susceptibility measurements. This is consistent with previous measurements on pure $\mathrm{Pu}$ between 4 and $600 \mathrm{~K}$ that showed almost the same susceptibility value for $\alpha-\mathrm{Pu}$ and $\delta-\mathrm{Pu}[26]$.

\section{Discussion}

\subsection{Deltagen effects and crystal structure}

The destabilization of the $\delta$ phase of Pu can be directly revealed by the presence, at room temperature and atmospheric pressure, of the $\alpha$-phase, or by the occurrence at lower temperature of the martensitic transformation $\delta \rightarrow \alpha^{\prime}$, $\alpha^{\prime}$ being monoclinic $\alpha$ with solute atoms trapped in the lattice. Whereas PuCe3.5\% is not monophased at room temperature ( $\gamma$ phase observed) all the other alloys, including the ternary alloys, are monophased with homogeneous grain size of about $40 \mu \mathrm{m}$ as measured by 

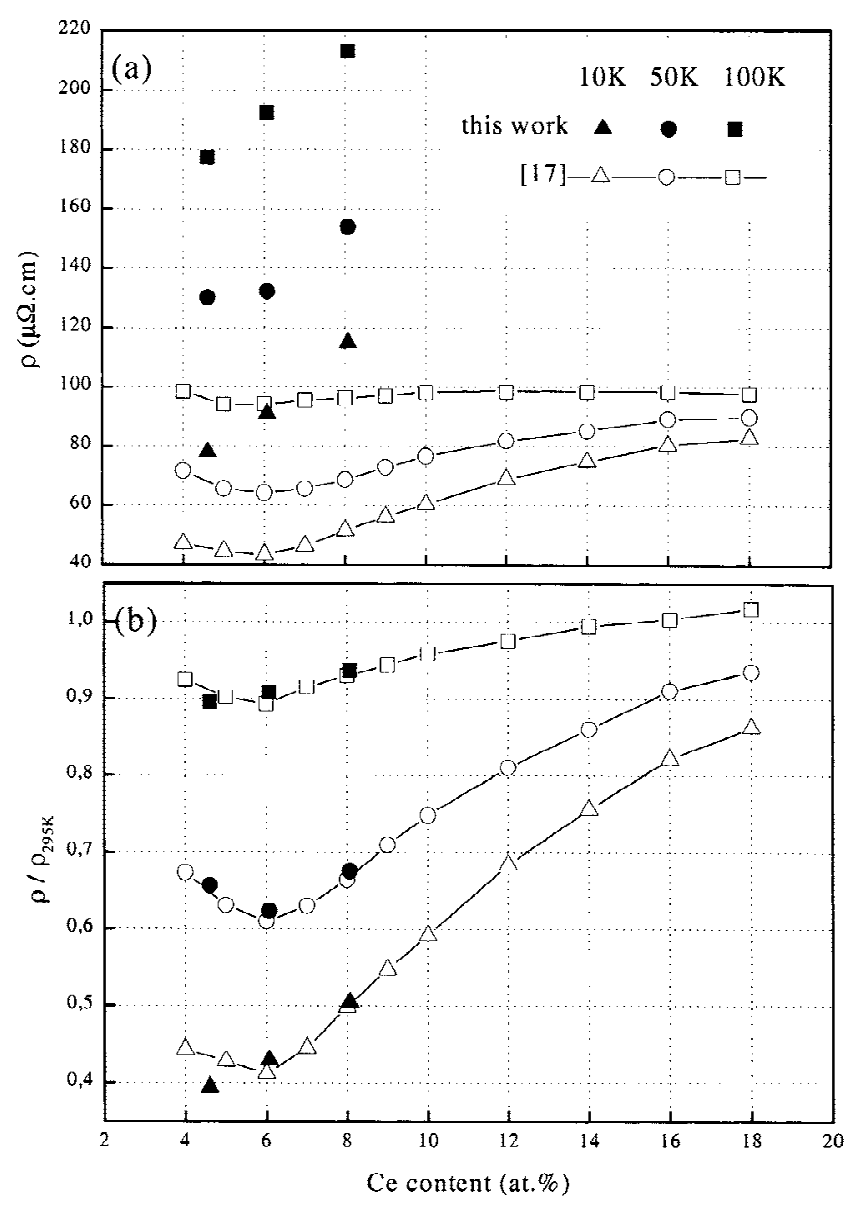

Fig. 5. Isotherms 10,50 and $100 \mathrm{~K}$ of electrical resistivity (a) and normalized electrical resistivity (b). For the alloys exhibiting a martensitic transformation, the resistivity curve has been extrapolated below the martensitic transformation temperature, with the assumption that the $\alpha$ phase occurrence induces only a translation of the curve (corresponding to the observed step) [17].

micrography. The coefficient of thermal expansion $\alpha$ including ternary alloys is higher than the one for the corresponding PuGa or PuCe binary alloys (Fig. 1); this

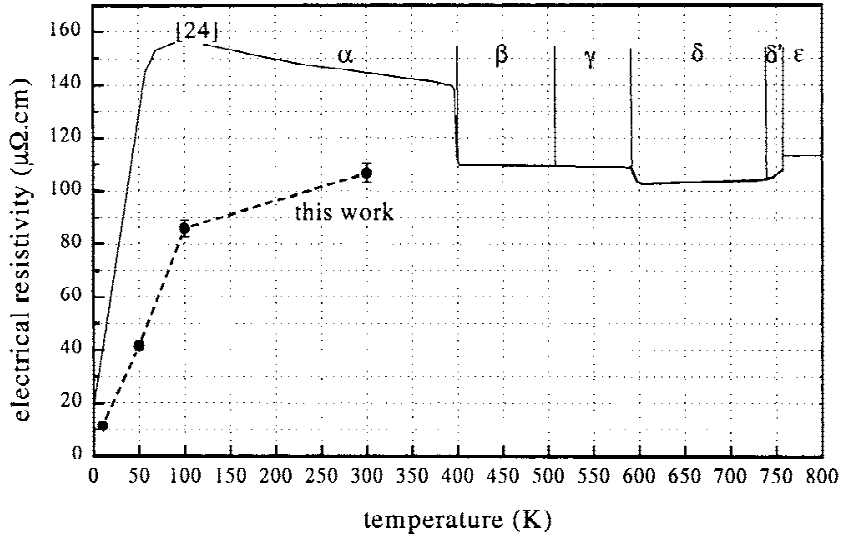

Fig. 7. Electrical resistivity of the $\delta$ phase extrapolated to low temperature and compared with electrical resistivity of pure $\mathrm{Pu}[24]$.

suggests that the deltagen effects of $\mathrm{Ce}$ and $\mathrm{Ga}$ are not antagonist. At low temperature $\delta$-PuCe $4.6 \%$ transforms to $\alpha^{\prime}$ (martensitic start temperature: $140 \mathrm{~K}$ ). There is no evidence of martensitic transformation in the other alloys including the ternary alloys which confirms the additive deltagen effects of $\mathrm{Ce}$ and $\mathrm{Ga}$.

$\mathrm{An}$ important result concerns the $\mathrm{Pu}-\mathrm{Pu}$ distances (obtained by EXAFS); the $\mathrm{Pu}-\mathrm{Pu}$ distances are indeed about $6 \%$ smaller than the mean distance obtained by XRD. This difference is definitely outside experimental errors and has a physical origin, being observed on several different alloys, using different synchrotron sources and models for analysis. While we do not have yet a satisfying explanation for this apparent contradiction, the unique behavior of $\mathrm{Ce}$ that can adapt its atomic volume (see next paragraph) may be at the origin of this result. The X-ray diffraction lines broadening observed for the $\mathrm{Pu}-\mathrm{Ce} 8.1 \%$ can not be attributed to a change in grain size which remains constant whatever the Ce content. It is tempting to draw a correlation between these results and the dipersion in $\mathrm{Pu}-\mathrm{Pu}$ and $\mathrm{Ce}-\mathrm{Pu}$ distances observed by EXAFS.
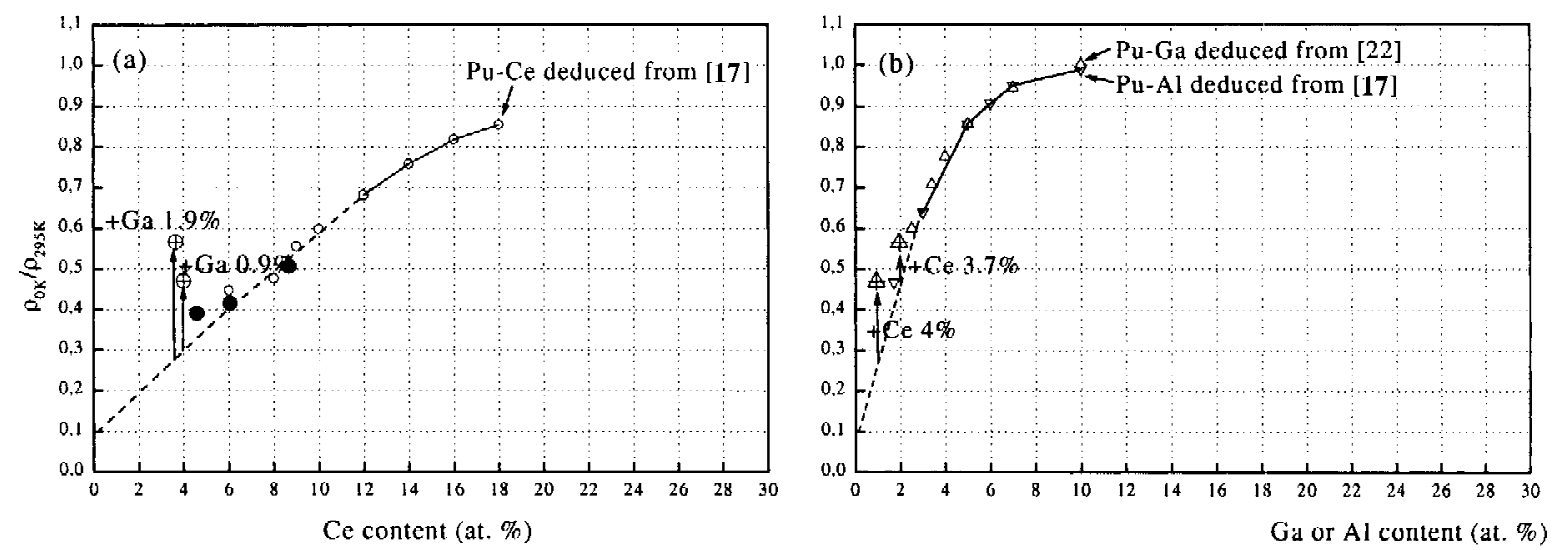

Fig. 6. Change in $\rho_{0 \mathrm{~K}} / \rho_{295 \mathrm{~K}}$ vs. Ce content (a) and Ga/Al content (b) for binary Pu-Ce ([17], this work), Pu-Ga [22], Pu-Al [17] alloys, and ternary $\mathrm{Pu}-\mathrm{Ce}-\mathrm{Ga}$ alloys (this work). 


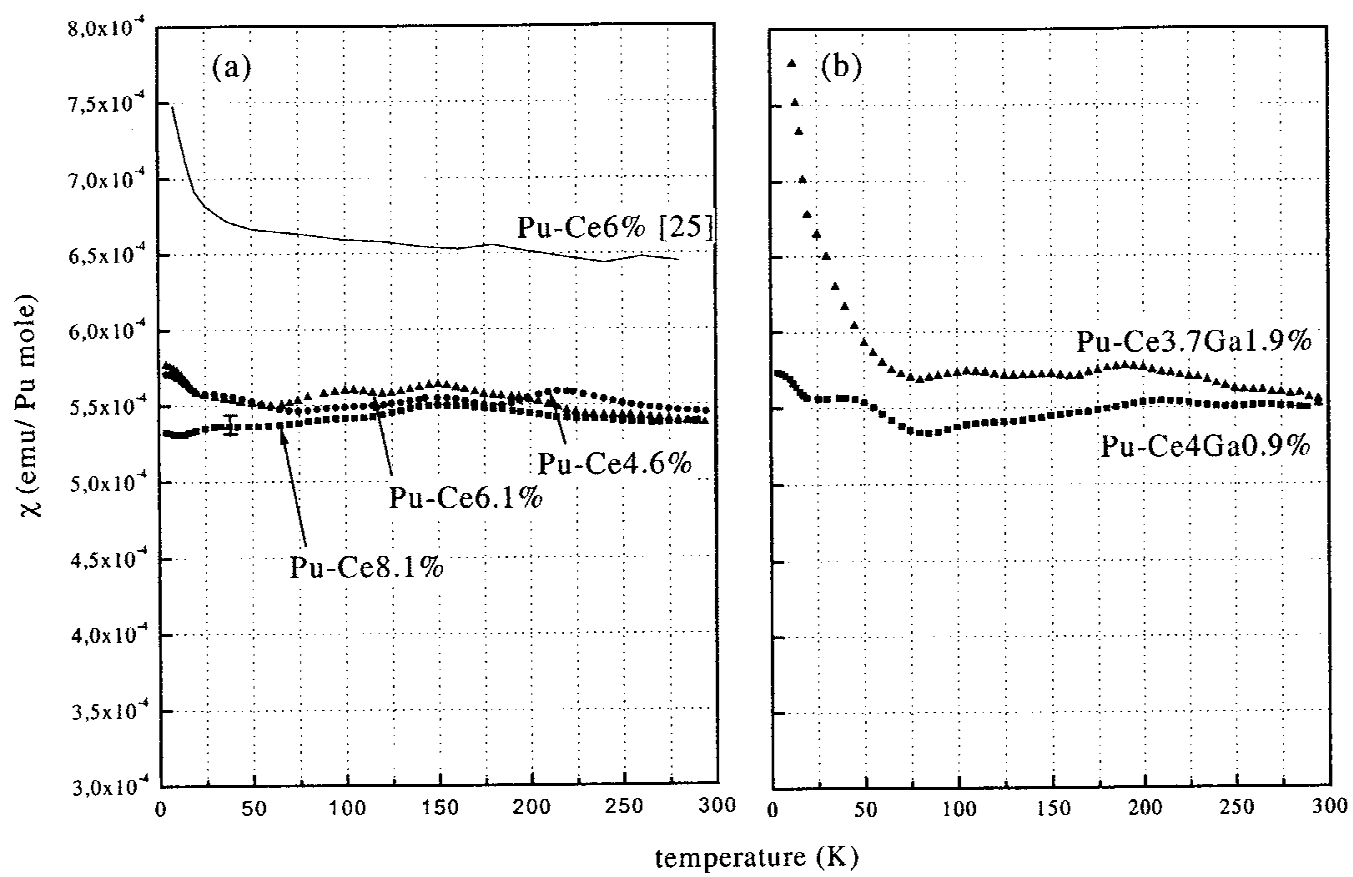

Fig. 8. Change in the magnetic susceptibility vs. temperature for binary $\mathrm{Pu}-\mathrm{Ce}$ ([25], this work) (a), and ternary Pu-Ce-Ga alloys (this work) (b). The signal increase observed under $70 \mathrm{~K}$ for the $\mathrm{Pu}-\mathrm{Ce} 3.7 \mathrm{Ga} 1.9 \%$ is thought to be due to the presence of a foreign phase in the sample.

\subsection{Electronic structure}

As recalled in the introduction, not only $\mathrm{Pu}$ but also $\mathrm{Ce}$ are extraordinary metals. They both have f electron states at the threshold of localization. They both show allotropic transformation involving huge volume changes $(21 \%$ increase for the $\alpha-\gamma$ transition in Ce, 24\% increase for the $\alpha-\delta$ transition in $\mathrm{Pu}$ ), which can be driven by temperature or by pressure.

In both cases this huge volume change has been related to a localization process of the $\mathrm{f}$ states: is this process exactly the same for $\mathrm{Ce}$ and $\mathrm{Pu}$ ? A comparative discussion is of some interest here for a better understanding of the $\mathrm{Pu}-\mathrm{Ce}$ alloys.

The expanded $\gamma$-Ce phase is clearly trivalent like a normal rare earth [27]: the one $4 \mathrm{f}$ electron state is atomiclike which is confirmed by the physical properties of $\gamma-\mathrm{Ce}$ starting with its atomic volume and its magnetic susceptibility. But as recalled in the Introduction this is not yet the case of expanded $\delta-\mathrm{Pu}$ and we can also say this is confirmed by its atomic volume and its magnetic susceptibility. If there is an overall agreement about a localization step between $\alpha-\mathrm{Pu}$ and $\delta-\mathrm{Pu}$, the precise behavior of the $5 \mathrm{f}$ states in $\delta-\mathrm{Pu}$ is still a subject of research and debate: they are strongly correlated but what is the exact nature of these correlated states?

We have proposed a Kondo-type intraatomic correlation between local $5 \mathrm{f}$ states and band states [25]: this was based on the $\log T$ dependence of the electrical resistivity at high temperature in all stabilized $\delta$-Pu alloys and recent results on irradiation effects in $\delta$ stabilized $\mathrm{Pu}$ alloys favor this approach [28]. Other models have also been proposed, all trying to reconcile essentially localized $5 \mathrm{f}$ states with a temperature independent susceptibility and a very large resistivity.

At the other end, while it is now generally agreed that $5 \mathrm{f}$ states in $\alpha-\mathrm{Pu}$ are band states, the case of $\alpha-\mathrm{Ce}$ is controversial: after the failure of the promotional model, inconsistent with photoemission results [29], Johansson [30] explained the $\gamma-\alpha$ transition as a Mott transition within the $4 \mathrm{f}$ electron shell, the $4 \mathrm{f}$ states becoming band states in $\alpha$-Ce. A Kondo Volume Collapse model was also proposed [31]. Calculations including combined SIC-LDA (Local-Density-Approximation) and Anderson impurity model [32] describe correctly some experimental results. Thus, it appears that the electronic structure of $\alpha$-Ce remains an open problem.

Table 2 summarizes this by sorting $\mathrm{Pu}, \mathrm{Ce}$ and $\mathrm{Am}$ comparing their $f$ electronic feature.

A striking singularity is observed in the f.c.c. $\mathrm{Pu}-\mathrm{Ce}$ solid solution, making it quite unusual and spectacular, as shown on Fig. 9 where the lattice parameter is plotted versus the Ce content for stable [20] and metastable [15] $\mathrm{Pu}-\mathrm{Ce}$ alloys. Above $75 \% \mathrm{Ce}$, the Vegard's law is well followed between $\delta-\mathrm{Pu}$ and $\gamma$-Ce. At $75 \% \mathrm{Ce}$, a drastic decrease in the lattice parameter occurs (3.8\%) which means that the Vegard's law between $\delta$-Pu and $\gamma$-Ce is not followed any more for lower Ce contents. Starting from low Ce contents, Ellinger [20] extrapolated his experimental results to $4.84 \AA$ at $100 \% \mathrm{Ce}$ : this parameter corresponds to $\alpha$-Ce under $1.5 \mathrm{GPa}$ [19] while a lattice of $4.96 \AA$ can be deduced for $\alpha$-Ce at ambient pressure, using the law 
Table 2

Electronic features of $\mathrm{Pu}, \mathrm{Ce}$ and $\mathrm{Am}$

\begin{tabular}{lll}
\hline Narrow $4 \mathrm{f} / 5 \mathrm{f}$ bands & Intermediate valent system & Localized $4 \mathrm{f} / 5 \mathrm{f}$ electrons \\
\hline$\alpha-\mathrm{Pu}$ & $\delta-\mathrm{Pu}$ & $\alpha, \beta-\mathrm{Am}$ \\
$\alpha^{\prime}-\mathrm{Ce}($ pressure $>4 \mathrm{GPa})$ & $\alpha-\mathrm{Ce} ?$ & $\gamma-\mathrm{Ce}$ \\
$\alpha-\mathrm{Ce} ?$ &
\end{tabular}

describing the Ce volume vs. pressure up to $10 \mathrm{GPa}$ [33]. Therefore, a second predicted lattice parameter evolution (with respect to the Vegard's law) is considered between $\delta$-Pu and $\alpha$-Ce. From it, a negative deviation occurs for both Ellinger's results (stable solid solutions) and Giessen's results [15] (metastable solid solutions).

Vegard's law being the signature of a pure steric behavior, deviations from it must be interpreted in terms of electronic effects. In the case of $\mathrm{Pu}-\mathrm{Ce}$ alloys, both $4 \mathrm{f}$ and 5f electrons are facing the localization process: any $\mathrm{f}$ localization leads to an increase in the volume of the corresponding atom. Then, both $4 \mathrm{f}$ electrons delocalization in $\mathrm{Ce}$ ( $\alpha$-Ce or, as shown in the Th-Ce system, $\gamma$-Ce [34]), which is due to the small $\delta$-Pu lattice, and $5 \mathrm{f}$ electrons localization in $\mathrm{Pu}$, due to large $\mathrm{Ce}$ atoms, must contribute. Above 75 at.\%Ce, a plot of the deviation with respect to the Vegard's law between $\delta$-Pu and $\gamma$-Ce shows a positive deviation for $\delta-\mathrm{Pu}-\gamma-\mathrm{Ce}$ alloys, as observed in the $\delta-\mathrm{Pu}-$ Am system (Fig. 10). 4f electrons being quite localized in $\gamma$-Ce, the deviation is associated with a preponderant localization of the $5 \mathrm{f}$ electrons in $\delta$-Pu. On the opposite, below 70 at. $\% \mathrm{Ce}$, the observed deviation from Vegard's law (between $\delta$-Pu and $\alpha-\mathrm{Ce}$ ) is negative, suggesting that the $4 \mathrm{f}(\mathrm{Ce})$ delocalization must be preponderant. At 70 at.\%Ce, the lattice stress due to the small $\mathrm{Pu}$ atoms corresponds to the pressure inducing the $\gamma$ to $\alpha$ transition in pure $\mathrm{Ce}$.

EXAFS measurements show a larger $\mathrm{Ce}-\mathrm{Pu}$ distance than $\mathrm{Pu}-\mathrm{Pu}$ distance, which confirms the steric effect of $\mathrm{Ce}$. Nevertheless, the $\mathrm{Pu}-\mathrm{Pu}$ distances do change with $\mathrm{Ce}$ content whereas the lattice parameter increases. Moreover, $\mathrm{Pu}-\mathrm{Pu}$ distances deduced from EXAFS are significantly different from those deduced from X-ray diffraction.

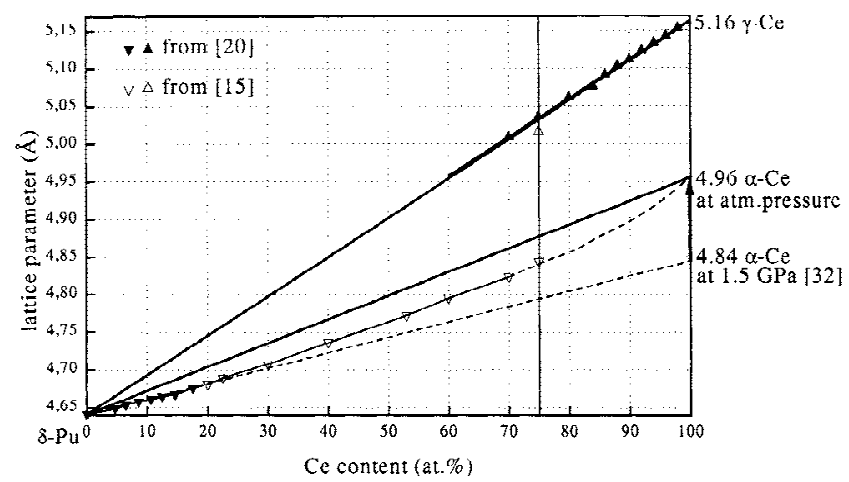

Fig. 9. Change in the lattice parameter of $\mathrm{Pu}-\mathrm{Ce}$ alloys vs. Ce content.
In $\mathrm{Pu}-\mathrm{Ga}$ alloys, the $\mathrm{Pu}-\mathrm{Pu}$ distances deduced from both EXAFS and XRD measurements are, on the contrary of $\mathrm{Pu}-\mathrm{Ce}$ alloys, the same [10] and change with gallium concentration.

The discrepancy between $\mathrm{Pu}-\mathrm{Pu}$ distances deduced from EXAFS and XRD measurements could be attributed to the averaging nature of the XRD measurements which are global while EXAFS are local ones. XRD distances could then be seen as a weighted average between $\mathrm{Pu}-\mathrm{Pu}$ and $\mathrm{Ce}-\mathrm{Pu}$ distances. This is consistent with the broadening of the XRD peaks observed in the PuCe8.1\% alloy. It would be interesting to have the $\mathrm{Pu}-\mathrm{Pu}, \mathrm{Ce}-\mathrm{Pu}$ distances and XRD results for higher cerium contents. In the case of $\mathrm{Pu}-\mathrm{Ga}$ alloys, the light gallium atoms barely contribute to the X-ray scattering compared to the heavy plutonium atoms. Nevertheless, it would be interesting to study more in detail the width of the XRD peaks as a function of gallium content.

Regarding the constant $\mathrm{Pu}-\mathrm{Pu}$ interatomic distances observed for the $\mathrm{Pu}-\mathrm{Ce}(-\mathrm{Ga})$ alloys, it suggests a weak effect of cerium on the localization of the $5 \mathrm{f}$ electrons states: this is consistent with the very similar magnetic susceptibility curves obtained.

Despite this apparent weak effect of $\mathrm{Ce}$ on the electronic structure of $\mathrm{Pu}$, this solute is not inert. Indeed, Ce addition in a $\mathrm{Pu}-\mathrm{Ga} 1 \%$ alloy makes the martensitic transformation disappear and leads to an increase in the $\delta$ phase expansion coefficient: this demonstrates that $\mathrm{Ga}$ and $\mathrm{Ce}$ have an additive effect regarding the $\delta$ phase stability.

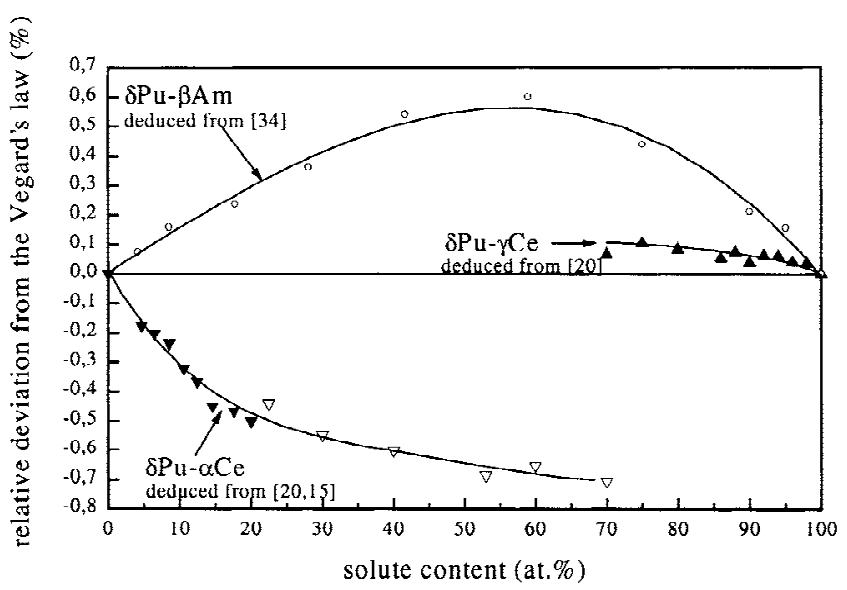

Fig. 10. Change in the relative deviation from the Vegard's law vs. solute content (lines are guides for the eyes). 


\section{Conclusion}

Understanding the effect of Ce upon the behavior of the $5 f$ electron states in $\delta$ stabilized $\mathrm{Pu}-\mathrm{Ce}(-\mathrm{Ga})$ solid solutions requires to know the precise organization of the atoms in the f.c.c. lattice, both at long and short range.

It appears that for low concentrations, $\mathrm{Ce}$ is $\alpha$-like, while for high concentrations (above 75\%) it is $\gamma$-like: the smaller size of $\mathrm{Pu}$ atoms induces an internal pressure which induces a $\gamma-\alpha$ transition in $\mathrm{Ce}$ as $\mathrm{Pu}$ is added to it. For low $\mathrm{Ce}$ concentrations $\alpha$-like Ce atoms appear quite soft and adapt their size to the requirements of $\mathrm{Pu}$ atoms. This rather unique behavior may be at the origin of the discrepancy between local and mean values of the $\mathrm{Pu}-\mathrm{Pu}$ distances, leading also to a weaker localization process of the $5 \mathrm{f}$ electrons than expected due to the increase in the lattice parameter with increased $\mathrm{Ce}$ content in the solid solution. Investigating other alloys with higher Ce content is necessary to get more information about the crystalline structure and about a possible sign of clear $5 \mathrm{f}$ localization. Moreover the high temperature expansion coefficient has been obtained for all $\delta$ stabilized Pu alloys as a function of concentration. This may be useful in better understanding the still unexplained negative thermal expansion of $\delta$-Pu.

The very important magnetic diffusion term in the electrical resistivity allows the use of normalized resistivity curves for the comparison of the different $\delta$-stabilized $\mathrm{Pu}$ alloys. The analysis then allows to obtain a full resistivity curve for $\delta$-Pu down to $0 \mathrm{~K}$ although $\delta-\mathrm{Pu}$ is not stable below $592 \mathrm{~K}$.

In ternary $\mathrm{Pu}-\mathrm{Ce}-\mathrm{Ga}$ alloys, the additive deltagen effects of $\mathrm{Ce}$ and $\mathrm{Ga}$ has been demonstrated.

\section{Acknowledgements}

We would like to express our appreciation to Professor J.C. Niepce for helpful suggestions and discussions. We also wish to thank Mrs V. Briois and Mrs S. Belin from LURE for helping with the EXAFS measurements.

\section{References}

[1] J. Bouchet, B. Siberchicot, F. Jollet, A. Pasturel, J. Phys. Condens. Matter 12 (2000) 1723.

[2] S.Y. Savrasov, G. Kotliar, E. Abrahams, Nature 410 (2001) 793.

[3] F.H. Ellinger, K.A. Johnson, C.C. Land, Los Alamos Scientific Laboratory, unpublished work as of June, 1967.

[4] V.I. Kutaitsev, N.T. Chebotarev, I.G. Lebedev, M.A. Andrianov, V.N. Konev, T.S. Menshikova, Plutonium 1965, Proceedings of the third International Conference on Plutonium, London, 1965, in: A.E.
Kay, M.B. Waldron (Eds.), United Kingdom Atomic Energy Authority, London, Chapman and Hall for the Institute of Metals (Eds.), 1967, p. 420.

[5] L. Pauling, J. Am. Chem. Soc. 69 (1947) 542.

[6] W.H. Zachariasen, J. Inorg. Nucl. Chem. 35 (1973) 3487.

[7] A.W. Lawson, T.Y. Tang, Phys. Rev. 76 (1949) 301.

[8] F.H. Ellinger, C.C. Land, V.O. Struebing, J. Nucl. Mat. 12 (2) (1964) 226.

[9] F.H. Ellinger, C.C. Land, W.N. Miner, J. Nucl. Mat. 5 (2) (1962) 165.

[10] Ph. Faure, B. Deslandes, D. Bazin, C. Tailland, R. Doukhan, J.M. Fournier, A. Falanga, J. Alloys Comp. 244 (1996) 131.

[11] L.E. Cox, R. Martinez, J.H. Nickel, S.D. Conradson, P.G. Allen, Phys. Rev. B 51 (1995) 751.

[12] P. Weinberger, A.M. Boring, J.L. Smith, Phys. Rev. B 31 (1985) 1964.

[13] A.M. Boring, J.L. Smith, Challenges in Plutonium Science, volume I, Los Alamos Science 26, in: N.G. Cooper (Ed.), Los Alamos National Laboratory, 90 (2000).

[14] B.R. Cooper, Challenges in Plutonium Science, volume I, Los Alamos Science 26, in: N.G. Cooper (Ed.), Los Alamos National Laboratory, 154 (2000).

[15] B.C. Giessen, V.O. Struebing, R.O. Elliott, Mat. Sci. Eng. 18 (1975) 239.

[16] T. Gouder, private communication.

[17] R.O. Elliott, C.E. Olsen, J. Louie, J. Phys. Chem. Solids 23 (1962) 1029.

[18] M. Taylor, J. Nucl. Mat. 31 (1969) 339.

[19] W.N. Miner, F.W. Schonfeld, Plutonium Handbook, in: O.J. Wick (Ed.), Pacific Northwest Laboratories, The American Nuclear Society, La Grange Park, Illinois, USA (1967).

[20] F.H. Ellinger, C.C. Land, E.M. Cramer, in: W.D. Wilkinson (Ed.), Extractive and Physical Metallurgy of Plutonium and its Alloys, Vol. 149, Interscience Publishers, New York, 1960.

[21] P. Villela, F.J. Espinosa-Faller, J.C. Lashley, S.D. Conradson, L.E. Cox, B. Martinez, R. Martinez, R. Pereyra, J. Terry, L. Morales, Phys. Rev. B, to be published.

[22] J. Joel, C. Roux, M. Rapin, J. Nucl. Mat. 40 (1971) 297.

[23] D.T. Peterson, D.F. Page, R.B. Rump, D.K. Finnemore, Phys. Rev. B 153 (3) (1967) 701

[24] R.B. Gibney, T.A. Sandenaw, internal report from Los Alamos, $n^{\circ}$ 1883 (1967).

[25] S. Méot-Reymond, J.M. Fournier, J. Alloys Comp. 232 (1996) 119.

[26] N. Buclet, J.M. Fournier, M. Dormeval, L. Jolly, F. Wastin, E. Colineau, J. Rebizant, G. Lander, $2^{\text {nd }}$ workshop on Orbital and Spin Magnetism of Actinides, Berkeley, October, 2002.

[27] A. Svane, Phys. Rev. B 53 (8) (1996) 4275.

[28] M. Fluss, to be published.

[29] D.M. Wieliczka, C.G. Olson, D.W. Lynch, Phys. Rev. B 29 (1984) 2028.

[30] B. Johansson, Philos. Mag. 30 (1974) 469.

[31] J.W. Allen, R.M. Martin, Phys. Rev. Lett. 49 (1982) 1106; R.M. Martin, J.W. Allen, J. Magn. Mater. 47\&48 (1985) 257.

[32] J. Lægsgaard, A. Svane, Phys. Rev. B 59 (5) (1999) 3450.

[33] K.A. Gschneidner Jr., Rare Earth Alloys, D. Van Nostrand Company, Princetown, NJ, 1961.

[34] J.H.N. van Vucht, Philips Res. Rep. 12 (1957) 351; R.T. Weiner, W.E. Freeth, G.V. Raynor, J. Inst. Metals 86 (19571958) 185 ;

D.S. Evans, G.V. Raynor, J. Nucl. Mat. 5 (3) (1962) 308. 